\title{
WHO'S WINNING THE BURGER WARS? A CLOSER LOOK AT SOCIAL NETWORKING, ENTERPRISE SOCIAL NETWORKS, AND CUSTOMER ENGAGEMENT
}

\author{
Philip Kim, Walsh University, pkim@walsh.edu
}

\begin{abstract}
Today, most businesses use social media externally for public relations and marketing purposes. Correspondingly, the majority of current research surrounding social media in business exists to educate companies about how to effectively communicate with consumers and promote their products and services. There is limited research on how organizations can leverage social media platforms to increase customer engagement. The paper examines and provides a literature review of social media technology and the impact on brand awareness and customer engagement.
\end{abstract}

Keywords: Social Networking, Enterprise Social Networks, Brand Awareness, and Customer Engagement

\section{INTRODUCTION}

Extending beyond the individual and even social communication purposes, organizations are now seeking ways to leverage social media platforms to increase customer engagement (Rick, 2010; Sashi, 2011). Social media continues to be a pervasive aspect of modern culture (GWI, 2018). According to the Statista Portal (2018), the total number of active social media users in 2017 is over $2.4 \mathrm{~B}$ users, and that number will increase to over 3.1B users by 2021 (Statista, 2018). Along with the ubiquity of mobile devices, social media usage continues to grow among consumers and online customers (Schivinski \& Dabrowski, 2016). As such, many businesses have adopted it as a tool to reach consumers and promote their products and services (Castronovo \& Huang, 2012). However, even though social media has experienced rapid growth over the past decade, there is still much uncertainty surrounding its place in business and its return on investment (Bratt, 2009). Many companies are unsure of how to use social media effectively and their efforts are often scattered and unfocused. In recent years, social media research has placed an emphasis on brand awareness and marketing to reach broader markets and to engage consumers more effectively (Kaplan \& Haenlein, 2010; Kietzmann, Hermkens, McCarthy, \& Silvestre, 2011; Patel, 2015; Safko \& Brake, 2009).

Traditional social media marketing emphasizes external uses of social media, such as marketing, branding, and public relations; however, it is also possible to use social media internally within a firm through enterprise social networks (Awolusi, 2012). The review of the literature yielded limited results when comparing external versus internal use of social media platforms. This paper explores whether increased social media engagement can have an impact on consumer behavior, specifically how customers interact within the social media platform to engage the organization.

\section{Evolution of Social Media}

During the relatively short time that social media has been in existence, it has evolved from a source of entertainment to an accepted form of online communication in which most employees choose to participate (Kaplan \& Haenlein, 2010). Social media began to gain traction in 1997, when a newly launched site called Six Degrees allowed users to create a profile and find friends, a play upon the 'six degrees of freedom' premise. Following the emergence of Six Degrees, blogging and instant messaging became a popular way for individuals to use the internet for social networking. The permeation of the internet grew throughout the early 2000s, and in 2003, MySpace became a popular social media platform for users to create a profile and communicate with friends online ("History of Social Media," n.d.).

Twitter was created in 2006 in response to the popularity of smart devices and text messaging. Twitter was unique because it allowed users to communicate with the world by sending out messages or tweets of 140 characters or less. In 2010, when Facebook and Twitter were well established in the market, many new social media platforms emerged, including photo sharing sites like Photobucket and Instagram, as well as microblogging sites like Tumblr and Plurk. 


\section{Issues in Information Systems \\ Volume 19, Issue 4, pp. 16-25, 2018}

It was also during this timeframe that social media became prominent in business. Companies began creating Facebook and Twitter profiles, and referring customers to those sites in advertisements. Today, companies use social media platforms to connect with consumers and market their products and services (Mangold \& Faulds, 2009). Even in just the past five years, social media has experienced substantial growth. "[Ninety-eight percent] of digital consumers are social media users and figures are high even among 55-64 year olds (94\%). An average of 2 hours and 15 minutes per day is spent on social networks and messaging" (GWI, 2018, p.7).

The impact that social media has had on commerce is significant. While social media was traditionally viewed as a way for users to consume content, it has now become a platform for users to create and share content. Individuals often use their social media accounts to share and discuss their opinions of companies, products, and complaints (Gensler, Völckner, Liu-Thompkins, \& Wiertz, 2013). This can have a significant effect on a brand's reputation. This is the social media phenomenon: there has been a power shift from the hands of marketing and public relations personnel to the general public in projecting the image of a brand (Berthon, Pitt, Plangger, \& Shapiro, 2012). This phenomenon has drawn the attention of most companies, as they seek to leverage social media in order to interact with these influential consumers. Companies also recognize the volume of individuals that participate in social media, and therefore see it as a way to achieve great reach in promoting their products or services (Kietzmann, Hermkens, McCarthy \& Silvestre, 2011). A casual observer can easily observe businesses' participation in social media through modern advertisements and packaging, where companies often direct consumers to their social media sites.

\section{SOCIAL MEDIA IN USE}

With the majority of Americans participating in social media, there is no question of its importance within today's society. However, with its rapid growth, there is much uncertainty surrounding it, especially related to business. Some still question whether social media should be used by business and in what capacity. While many companies have chosen to dive into social media by creating profiles on many platforms, and beginning to interact with consumers a number of corporate leaders are unsure of how and where exactly to integrate social media into their businesses. This lack of understanding of social media's forms and purposes has caused a sense of resistance related to whether social media should be an integral part of a business' strategy (Kietzmann, Hermkens, McCarthy, \& Silvestre, 2011).

Social media now drives more traffic to websites than search engines. Due to the sheer volume of traffic to social media, business experts are proclaiming that firms must participate in social media in order to be successful (Holmes, 2015; Patel, 2015). The four most popular social networks based on overall usage are: Facebook, Instagram, Snapchat, and Twitter (Chaffey, 2018).

\section{Purpose of Social Media in Business}

As previously stated, leaders and decision makers in business are often disorganized about the purpose of social media in business. For example, how can it be integrated into the company's strategy and how should resources be allocated? In recent years, research has been published to mitigate the misunderstanding of social media and educate companies on how to effectively leverage it. This has helped to shed light on how companies can use social media to best reach consumers.

Although most companies have social media accounts, their efforts are rarely focused enough to achieve maximum efficiency in communicating with their target consumers. Researchers recommend that firms conduct a thorough social media audit in order to clean up their participation in social media, and choose only the platforms that target their specific markets. They also stress the importance of ensuring that all of the firm's social media activities are aligned with its promotional strategy (Safko \& Brake, 2009). Current research also instructs companies on how to behave in their online interactions with consumers through social media. Writers suggest that companies remain actively engaged with consumers who show interest in their products and services (Kaplan \& Haenlein, 2009). They also suggest that firms maintain a tone of humility and relatability, and avoid being too professional to truly connect with consumers (Patel, 2015).

Social media is currently being leveraged by businesses as a marketing and public relations tool, to gain better insight and access to consumers. The vast majority of current research aims to assist companies in using social media externally as a way to promote its products or brand. However, there is a smaller amount of research which suggests 


\section{Issues in Information Systems \\ Volume 19, Issue 4, pp. 16-25, 2018}

that there are other ways that social media can be utilized by businesses, and perhaps there is significant value that has been overlooked. For example, Ryan Holmes of Hootsuite points out that email has historically been accepted as a necessity in business communication. However, email has slowly given way to more collaborative alternatives like instant messaging and wikis. New instant messaging platforms feature tools similar to those of Facebook, where employees form virtual groups for exchanging ideas. This is an example of how social media platforms may further permeate the workplace in the future, in an internal rather than external capacity (Holmes, 2012). This eludes to potential hidden value which evokes further exploration.

\section{External versus Internal Social Media}

As previously stated, while social media technologies are widely used for external purposes such as driving sales and increasing brand exposure, many companies have not yet explored the internal benefits it can provide. Social media has the potential to become a new office productivity tool within organizations to steam line systems and processes, generate idea sharing, centralize pertinent content and information, and ultimately increase collaboration across an enterprise. Social media technologies used within an organization are also referred to as enterprise social networks (ESN) (Awolusi, 2012). A survey conducted by McKinsey \& Co. (2012) showed that 70 percent of respondent companies are using social media for business purposes with 90 percent seeing a benefit from using said social media tools. However, the results of the survey also indicated that only 3 percent of companies are fully leveraging the capabilities social media technologies can provide (Chui et al, 2012). This further supports that social media as a means to increase customer engagement tool is still a relatively new and unexplored concept.

One of the key benefits realized from social media technology is improved communication and collaboration across an enterprise. The average professional worker spends approximately 65 percent of daily work time communicating with others (Chui et al, 2012). This includes activities such as e-mailing, attending meetings, and tracking down required information. Implementing social media platforms across an enterprise can reduce time spent on the prior mentioned activities that ultimately affect an organization's overall productivity. McKinsey \& Co. (2012) estimates that organizations that effectively introduce social media platforms into business processes have the potential to increase productivity by 20 to 25 percent (Chui et al, 2012). An independent report developed by AT\&T also noted that social media tools and technologies used in a business setting lead to increased efficiency (AT\&T, 2008).

Collaboration often happens within an informal group of individuals (Awolusi, 2012). This indicates that the rigidity of hierarchical reporting structures that are placed around employees is not where idea generation and collaboration is taking place. Executive leadership within companies often ignore the benefit of informal networks and informal collaboration taking place. Research indicates that such informal networks consistently provide both strategic and operational value to the greater organization (Cross, Borgatti, \& Parker 2012). Social media technologies have the ability to act as a catalyst in generating increased informal collaboration. It would serve as an additional medium for communication between members of an informal network with the speed and scale of internet and social media technologies. Such informal networks have the capacity to drive a competitive advantage of an organization within its respective industry (Gravili, n.d.). Mckinsey \& Co. (2012) estimates that successfully implemented enterprise social platforms have the potential to create $\$ 900$ billion to $\$ 1.3$ trillion in annual value creation within the industries studied. Two-thirds of this value creation would be derived from expanded communication and collaboration processes across all sectors of an organization (Chui et al, 2012). The true value and full-capability of social media platforms used in business is not fully understood as it is still developing. What is understood is that a shift to enterprise social networks is inevitable. Ignoring the hidden value of leveraging such technologies may result in a loss of competitive advantage (Aguenza, Al-Kassem, \& Mat Som 2012).

\section{Improving Collaboration and Communication Leveraging Social Media Technologies}

Collaboration and communication drives knowledge sharing and idea generation within an enterprise. Knowledge sharing involves helping others comprehend a given topic, communication to solve daily issues, generating new ideas, and developing innovative solutions to complex problems (Gaál, Szabó, Obermayer-Kovács, \& Csepregi, 2015). This is important within any industry but is crucial for companies participating in knowledge-intensive industries. Knowledge-intensive environments require collaboration among and across many groups with different knowledge bases and skill sets.

Collaboration among different groups is what drives problem solving and idea generating in such settings (Cross, Borgatti \& Parker 2012). Knowledge is an integral resource both operationally and strategically. If leveraged and 
managed effectively, it can produce a sustainable competitive advantage (Gaál, Szabó, Obermayer-Kovács, \& Csepregi, 2015). Social media technologies offer new ways to exploit knowledge sharing and foster increased customer engagement, feedback, and responses.

Improved knowledge-sharing is achieved through the use of enterprise social media technologies due to several key functionalities it provides. At its highest level, social media networks allow a customer faster access to information and solutions to support their respective interests. Social media technologies would create a centralized hub of information and knowledge where all stakeholders could quickly and efficiently access. All posted content is accessible, organized, and searchable to all who would potentially want to view it.

Additionally, internal stakeholders can be impacted as well. Operational silos that inhibit communication that are present within every organization would be reduced as information is available in one location versus one department. The ability to collaborate with teams in different geographic locations would also be made easier as more fluid knowledge sharing would be in place. More knowledge sharing and faster insight generation would be realized by having a searchable and structured communication portal. Time spent searching for information could be reduced by as much as 35 percent (Chui et al, 2012). Content posted by individual employees also can be tracked. Management can then review posted content and use it as a way to further evaluate an employee's respective performance. This can also be used as a talent matching tool to better place certain employees in better fittings roles and recognize them for their work. Matching the correct skill set with the right position will naturally increase productivity as well. The increased ability within social media networks increases communication and collaboration capabilities derived from an enterprise social network have the potential to improve and change the onboarding process of new employees and outside contractors. New employees would spend less time searching for answers and tracking down an internal expert because information would all be in an organized and searchable location. Hired consultants would decrease time spent searching for the specific process owner and subject matter expert because it would all be published on the organization's internal social media platform. Overall, the combination of all the prior mentioned benefits would result in reduced operational costs for the organization. This would be realized due to less required travel costs as virtual collaboration would be the primary method. Talent recruitment and hiring processes could also be conducted virtually rather than spending budget dollars on traditional recruiting methods. The combined impact of reduced operational costs and increased collaboration and productivity, result in value creation for the respective organization.

\section{Social Media and Empathy}

Stevens and Ross (2016) examined University of Florida's UF Health social media presence, examining how using social media to focus on patient successes, caregivers, and community achievements allowed the organization to create a more empathetic culture. Similarly, Maben and Gearhart (2018) reiterated that social media managers can incorporate "verbal listening behaviors" and cues into their social media profiles to allow for a more empathy-driven user experience. Their example-laden research discussed active listening strategies, which include personalizing responses to customers and elaborating on topics consumers are discussing. Maben and Gearhart (2018) called for future research into what components of empathic engagement are specific to social media, as well as into what consumer expectations actually are for social media engagement. Interestingly, Palledo and Tar (2016) suggest that social media can be especially powerful when used by individuals and organizations seeking to share illness narratives and cultivate empathy in their audience. Their study examined how pain narratives on Flickr and Tumblr are transformed by the visual, multimodal elements of the sites. Flickr allows for the audience to experience the immediacy of stories and this elicits empathy; meanwhile, Tumblr creates support communities and can build empathy through social criticism. Palledo and Tar's (2016) research, which is especially applicable to healthcare organizations, suggests illness can be easier for others to understand and emphasize with through social media. Is empathy a necessary component in engaging the external stakeholder?

Specific attention has been given to how empathy relates to communication, even in a mediated environment such as virtual reality. Schutte and Stilinović (2017) developed a study in which participants viewed the story of a child in a refugee camp either in a virtual reality format or a two-dimensional format. When audience levels of empathy were measured, they were found to be significantly higher for those who viewed the story in a virtual reality format. The researchers concluded that virtual reality can indeed influence interpersonal emotions like empathy, and recommended future research on how virtual reality can impact effective communication and emotional expression. Meanwhile, research by Shin (2018) examined how the user experience of virtual reality affected presence, empathy, and feelings of embodiment, finding that user experience of virtual reality differed greatly according to individual experience. 


\section{Issues in Information Systems \\ Volume 19, Issue 4, pp. 16-25, 2018}

According to Shin (2018), there is a strong human component that affects how users are influenced by virtual reality stories and whether they empathize with them. If further research confirms Schutte and Stilinović (2017)'s hypothesis that virtual reality can increase empathy levels, social media managers should be aware of how this can impact the level of engagement with the consumer.

\section{Successful Social Media Technology Implementations}

Although enterprise social networks and their corresponding benefits have not yet been researched and explored to full potential, there are several instances of companies who have successfully implemented such technologies. Unisys is a global information technology company serving as a consultant to solve complex information technology issues for large companies and governments (Unisys, 2018). Unisys launched an internal social network with the main purpose of improving collaboration amongst its 20,000 employees located across the world. More specifically, the company wanted the implemented platform to serve as a social site for technical experts to solve complex problems together and for others to have access to their work. Of its 20,000 employees, 16,000 employees joined the internal social site (approximately an 80 percent adoption rate) (Chui et al, 2012). A partial reason for the successful implementation and adoption rate is the benefits users were able to derive from using the internal social site. Employees were quickly able to see the efficiency and value-creating benefits of continuing to use the new internal social site and continued to leverage it (Chui et al, 2012).

Unisys is hardly the only company to experiment with internal social networks. In 2011, TD Bank Group that has 85,000 employees worldwide, implemented its own internal social networking site. The primary goal of implementing the new tool was to increase collaboration and engagement between its large number of employees. The organization has experienced just that since the social site's implementation. Thousands of employees have created profiles on the organization's internal social site. Some of the most notable, and expected, benefits are a reduction of e-mail, meetings, phone calls, and time spent searching for information (Chui et al, 2012).

A study that focused on the use of social media within organizations to increase organizational knowledge sharing found that $79 \%$ of global fortune 100 companies are currently using some form of social media and $20 \%$ are using all four major platforms (Facebook, Instagram, Twitter, and LinkedIn) of social media. (Ellison, Gibbs \& Weber, 2014). A significant majority ( $86 \%$ ) of managers believe that social media will be important within their industry in the next three years, primarily for external communication (Kiron, Palmer, Phillips, \& Kruschwitz, 2012).

\section{Burger Wars}

Certain industries may lend themselves better than others when it comes to social media engagement. For instance, it may be more challenging for heavily regulated industries (e.g. pharmaceutical, investment firms, and healthcare services) to openly share information online due to privacy and security mandates. Social media may allow for more agile use of information, but in some cases this is not the intended goal. For instance, a state's ongoing military operations may be compromised on an open social network (Mayfield, 2006).

Fast food continues to be an arena for creative and brand-driven marketing. From the early days of promoting films, TV shows, celebrities, and athletes, fast food restaurants have driven the consumer-centric approach to brand awareness and customer engagement. Social media has amplified this reach.

Social media binds together communities that once were geographically isolated, greatly increasing the pace and intensity of collaboration. Now that these once-remote communities are densely networked, their cultural influence has become direct and substantial. These new 'crowd cultures' come in two flavors: subcultures, which incubate new ideologies and practices, and art worlds, which break new ground in entertainment. (Holt, 2016, p.43)

A recent example of the power of social media is Wendy's versus McDonald's a revived "Burger War" for today's social media consumer. What began as a social experiment has grown into a full-fledged marketing war between the two multi-billion dollar corporations. Note in Table 1 the top 10 fast food Twitter according to the number of followers: 


\section{Issues in Information Systems}

Volume 19, Issue 4, pp. 16-25, 2018

Table 1. Top 10 Twitter Followers - Fast Food

\begin{tabular}{llll}
\hline & Followers & Tweets: & Likes: \\
\hline \hline McDonald's & $3.59 \mathrm{M}$ & $436 \mathrm{~K}$ & $3.6 \mathrm{~K}$ \\
\hline Wendy's & $2.55 \mathrm{M}$ & $128 \mathrm{~K}$ & $28.9 \mathrm{~K}$ \\
\hline Subway & $2.47 \mathrm{M}$ & $48.8 \mathrm{~K}$ & $10.8 \mathrm{~K}$ \\
\hline Taco Bell & $1.91 \mathrm{M}$ & $790 \mathrm{~K}$ & $28.6 \mathrm{~K}$ \\
\hline Burger King & $1.63 \mathrm{M}$ & $20.5 \mathrm{~K}$ & $7.3 \mathrm{~K}$ \\
\hline Pizza Hut & $1.61 \mathrm{M}$ & $408 \mathrm{~K}$ & $11 \mathrm{~K}$ \\
\hline KFC & $1.29 \mathrm{M}$ & $37.3 \mathrm{~K}$ & $6 \mathrm{~K}$ \\
\hline Domino's & $1.27 \mathrm{M}$ & $344 \mathrm{~K}$ & $6.7 \mathrm{~K}$ \\
\hline Chipotle & $889 \mathrm{~K}$ & $721 \mathrm{~K}$ & $69.3 \mathrm{~K}$ \\
\hline Chik-Fil-A & $921 \mathrm{~K}$ & $107 \mathrm{~K}$ & $7.4 \mathrm{~K}$ \\
\hline
\end{tabular}

Now compare that same list of Twitter accounts, but in Table 2 the ranking will be in descending order of the amount of "Likes" for the account, that is how many times the Twitter account has liked something and engaged with a follower:

Table 2. Top 10 Twitter Likes - Fast Food

\begin{tabular}{llll}
\hline & Followers & Tweets: & Likes: \\
\hline \hline Chipotle & $889 \mathrm{~K}$ & $721 \mathrm{~K}$ & $69.3 \mathrm{~K}$ \\
\hline Wendy's & $2.55 \mathrm{M}$ & $128 \mathrm{~K}$ & $28.9 \mathrm{~K}$ \\
\hline Taco Bell & $1.91 \mathrm{M}$ & $790 \mathrm{~K}$ & $28.6 \mathrm{~K}$ \\
\hline Pizza Hut & $1.61 \mathrm{M}$ & $408 \mathrm{~K}$ & $11 \mathrm{~K}$ \\
\hline Subway & $2.47 \mathrm{M}$ & $48.8 \mathrm{~K}$ & $10.8 \mathrm{~K}$ \\
\hline Chik-Fil-A & $921 \mathrm{~K}$ & $107 \mathrm{~K}$ & $7.4 \mathrm{~K}$ \\
\hline Burger King & $1.63 \mathrm{M}$ & $20.5 \mathrm{~K}$ & $7.3 \mathrm{~K}$ \\
\hline Domino's & $1.27 \mathrm{M}$ & $344 \mathrm{~K}$ & $6.7 \mathrm{~K}$ \\
\hline KFC & $1.29 \mathrm{M}$ & $37.3 \mathrm{~K}$ & $6 \mathrm{~K}$ \\
\hline McDonald's & $3.59 \mathrm{M}$ & $436 \mathrm{~K}$ & $3.6 \mathrm{~K}$ \\
\hline
\end{tabular}

Note the number of followers doesn't necessarily correlate to higher levels of customer engagement. However, the number of "Likes" may be a better indicator of engagement, interactivity, and discourse between the organization and the consumer (Holt, 2016).

Wendy's Twitter account has been actively engaged in social media through its unconventional and somewhat controversial interactions with customers, fans, detractors, and other businesses alike. In March 2018, McDonald's made an announcement of their intention to switch from frozen hamburger patties to fresh beef. Wendy's Twitter took this as an opportunity to openly mock McDonald's Twitter post. At that time, while the original post from McDonald's only received a few thousand likes, the Wendy's Twitter reply (Figure 1) garnered over 180,000 likes, and almost 80,000 customer comments (May, 2017). 


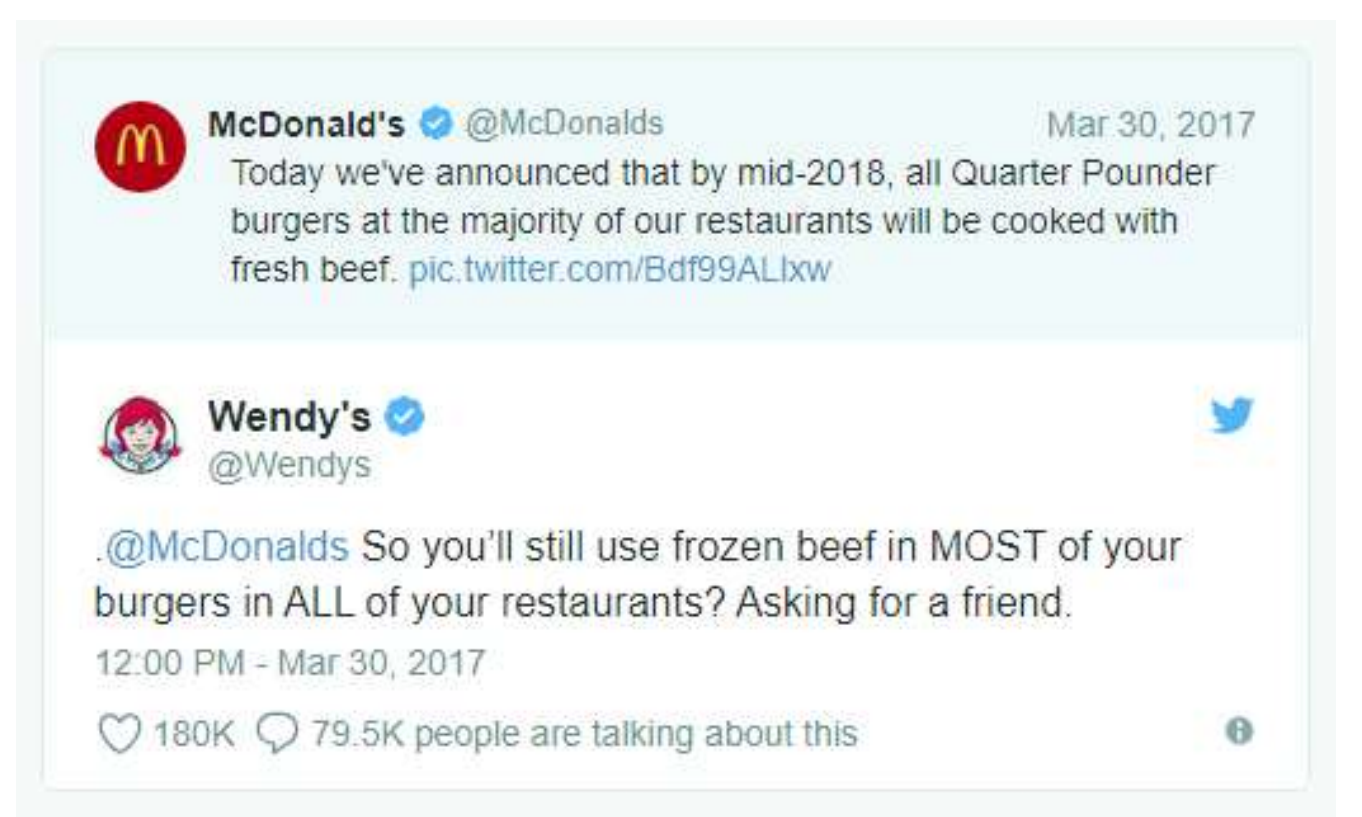

Figure 1.

\section{DISCUSSION}

Social media technologies have evolved tremendously since initial development. What began as a source of social communication is now also used as a lucrative business tool to drive product sales, promote brand exposure, and directly connect with consumers. While social media technologies are widely used for external purposes many companies have not yet explored how to increase customer engagement. Social media has the potential to become a new productivity tool within organizations to streamline systems and processes, generate ideas, centralize pertinent content and information, and ultimately increase customer loyalty across an enterprise. McKinsey \& Co. (2012) estimates that organizations that effectively introduce social media platforms into business processes have the potential to increase innovation by 20 to 25 percent (Chui et al, 2012). This increased productivity and innovation could result in significant value creation for organization.

Ellison, Gibbs, and Weber (2014) utilized an affordance-based approach to the study of social networks and delineated between traditional social network sites (SNS) and enterprise social networking sites (ESN). The affordance-based approach (Gibson, 1986) explains how the same object, artifact, or tool can be perceived differently based on the usefulness of the object. The affordance of the object or technology is significantly tied to the perceptions and goals of its users (Orlikowski, 1992). Therefore, Table 3 summarizes the distinction between the individual acting in their own interest and the individual acting on behalf of the organization (Ellison, Gibbs, \& Weber, 2014). 
Table 3. Key Differences Between SNSs and ESNSs

\begin{tabular}{lll} 
User Behavior & $\begin{array}{l}\text { Influenced by site norms, which may be } \\
\text { understood differently among users }\end{array}$ & $\begin{array}{l}\text { user guidelines and/or by informal team or } \\
\text { organizational norms }\end{array}$ \\
\hline Users & $\begin{array}{l}\text { Any individual who creates an } \\
\text { account and agrees to the site's } \\
\text { terms of service and other policies }\end{array}$ & $\begin{array}{l}\text { Employees of an organization; use } \\
\text { can be optional, encouraged, or } \\
\text { mandated }\end{array}$ \\
\hline Design & $\begin{array}{l}\text { Generally controlled by a parent } \\
\text { corporation, but designed to } \\
\text { encourage interaction among } \\
\text { individual users }\end{array}$ & $\begin{array}{l}\text { Generally controlled by } \\
\text { stakeholders within the } \\
\text { organization, but designed to } \\
\text { encourage interaction among } \\
\text { individual, teams, and other units }\end{array}$ \\
\hline Audience & $\begin{array}{l}\text { Can be global, limited to one's } \\
\text { entire friend network, or targeted } \\
\text { to subsets of one's articulated network }\end{array}$ & $\begin{array}{l}\text { Configured by user or possibly } \\
\text { organizational structure (work } \\
\text { team, department, and division) }\end{array}$ \\
\hline & & \\
Goals & & $\begin{array}{l}\text { Primarily used to accomplish } \\
\text { work-related goals, such as } \\
\text { knowledge sharing and forming } \\
\text { or maintaining connections with } \\
\text { professional contacts }\end{array}$ \\
\hline
\end{tabular}

While most organizations have not delineated between internal and external social media platforms, there are opportunities to focus efforts to further engage the consumer. When planning for a social media strategy organizations must consider how who their target audience is, what user groups they belong to, and what their goals are. For instance if one of the primary goals of the consumer is to build social capital (Gil de Zúñiga, Jung, \& Valenzuela, 2012), then organizations should seek to invite and engage with other like-minded fans to join the discussion. If the goal is to entertain, then organizations should be willing to provide the appropriate content to meet their consumers' demands. Organizations that seek to engage their customers, stakeholders, and employees should consider the affordance-based approach to interacting on social media, and seek to proactively draw their customers in.

\section{REFERENCES}

AT\&T. (2008). Social networking in the workplace increases efficiency. AT\&T. Retrieved from http://www.corp.att.com/emea/insights/pr/eng/social_111108.html.

Aguenza, B. B., Al-Kassem, A., \& Mat Som, A. (2012). Social media and productivity in the workplace: Challenges and constraints. Interdisciplinary Journal of Research in Business, 2(2), 22-26.

Awolusi, F. (2012, January). The impact of social networking sites on workplace productivity. The Journal of Technology, Management, and Applied Engineering, 28(1), 1-5. 
Berthon, P. R., Pitt, L. F., Plangger, K., \& Shapiro, D. (2012). Marketing meets web 2.0, social media, and creative consumers: Implications for international marketing strategy. Business Horizons, 55(3), 261-271.

Bratt, E. (2009). Dell outlet. In social media ROI success stories. Retrieved from http://marketingprofs.com.

Castronovo, C. \& Huang, L. (2012). Social media in an alternative marketing communication model. Journal of Marketing Development and Competitiveness, 6(1), 117-134.

Chaffey, D. (2018). Global social media research summary 2018. Smart Insights. Retrieved from: http://www.smartinsights.com/social-media-marketing/social-media-strategy/new-global-social-mediaresearch.

Chui, M., Manyika, J., Bughin, J., Dobbs, R., Roxburgh, C., Sarrazin, H., Sands, G., Westergren, M. (2012). The social economy: Unlocking value and productivity through social technologies. Mckinsey Global Institute, 6-48.

Cross, R., Borgatti, S. P., \& Parker, A. (2012). Making invisible work visible: Using social network analysis to support strategic collaboration. California Management Review, 44(2), 25-45.

Ellison, N. B., Gibbs, J. L., \& Weber, M. S. (2014). The use of enterprise social network sites for knowledge sharing in distributed organizations. American Behavioral Scientist, 59(1), 103-123.

Gaál, Z., Szabó, L., Obermayer-Kovács, N., \& Csepregi, A. (2015). Exploring the role of social media in knowledge sharing. The Electronic Journal of Knowledge Management, 13(3), 185-197.

Gensler, S., Völckner, F., Liu-Thompkins, Y., \& Wiertz, C. (2013). Managing brands in the social media environment. Journal of Interactive Marketing, 27(4), 242-256.

Gil de Zúñiga, H., Jung, N., \& Valenzuela, S. (2012). Social media use for news and individuals' social capital, civic engagement and political participation. Journal of Computer-Mediated Communication, 17, 319-336.

Gibson, J. J. (1986). The ecological approach to visual perception. Hillsdale, NJ: Lawrence Erlbaum.

Gravili, G. (2010). Can cooperation in virtual social networks help organizations manage knowledge? (Proceedings of the European Conference on Information Management \& Evaluation, pp. 109-117).

History of Social Media. (n.d.). History of social media. Retrieved June 10, 2016, from http://historycooperative.org/the-history-of-social-media.

Holmes, R. (2012). 5 ways social media will change the way you work in 2013. Retrieved from http://www.forbes.com/sites/ciocentral/2012/12/11/5-ways-social-media-will-change-the-way-you-workin-2013/\#1a9109d19d9b.

Holmes, R. (2015). Why businesses can't survive without social media. Retrieved from http://fortune.com/2015/11/18/businesses-cant-survive-social-media.

Holt, D. (2016). Branding in the age of social media. Harvard Business Review, March 2016.

Kaplan, A. M., \& Haenlein, M. (2010). Users of the world, unite! The challenges and opportunities of social media. Business Horizons, 53(1), 59-68.

Kietzmann, J. H., Hermkens, K., McCarthy, I. P., \& Silvestre, B. S. (2011). Social media? Get serious! Understanding the functional building blocks of social media. Business Horizons, 54(3), 241-251. 


\section{Issues in Information Systems}

Volume 19, Issue 4, pp. 16-25, 2018

Kiron, D., Palmer, D., Phillips, A. N., \& Kruschwitz, N. (2012). Social business: What are companies really doing? MIT Sloan Management Review 2012, Social Business Global Executive Study and Research Project. Cambridge, MA: Sloan Management Review.

Mangold, W. G., \& Faulds, D. J. (2009). Social media: The new hybrid element of the promotion mix. Business Horizons, 52(4), 357-365.

Mayfield, A. (2006). What is social media? Spannerworks. Retrieved from http://www.spannerworks.com/fileadmin/uploads/eBooks/What_is_Social_Media.pdf.

May, A. (2017). Sorry McDonald's, Wendy's twitter account is winning the war on beef. https://www.usatoday.com/story/money/nation-now/2017/03/31/sorry-mcdonalds-wendys-twitter-accountwinning-war-beef/99861576.

Orlikowski, W. J. (1992). The duality of technology: Rethinking the concept of technology in organizations. Organization Science, 3, 398-427.

Patel, S. (2015, June 24). How businesses should be using social media in 2015. Forbes. Retrieved from http://www.forbes.com/sites/sujanpatel/2015/06/24/how-businesses-should-be-using-social-media-in2015/\#7a7aafd24a5b.

Qualman, E. (2009). Socialnomics how social media transforms the way we live and do business. Hoboken, NJ: Wiley John \& Sons, Inc.

Rick, T. (2010). Social media changes customer service landscape. Retrieved from: http://www.torbenrick.eu/blog/customer-service/social-media-changes-customer-service-landscape.

Safko, L., \& Brake, D. (2009). The social media bible: Tactics, tools, and strategies for business success. Choice Reviews Online, 47(01).

Sashi, C. M. (2011). Customer engagement, buyer-seller relationships, and social media. Management Decision, $50(2)$.

Schivinski, B., \& Dabrowski, D. (2016). The effect of social media communication on consumer perceptions of brands. Journal of Marketing Communications, 22(2), 189-214.

Statista. (2018). Statista social media statistics portal 2018. Retrieved from: https://www.statista.com/statistics/278414/number-of-worldwide-social-network-users.

Unisys. (2018). Unisys - About us. Retrieved from http://www.unisys.com/about-us. 